\title{
Isolation and Biochemical Characterization of Indigenous Rhizobium Strains from Root Nodules of Field Grown Soybean Crop
}

\author{
Shanti ${ }^{*}$, Diptimayee Dash and Tapas Chowdhury \\ Department of Agricultural Microbiology, Indira Gandhi Krishi Vishwavidyalaya, \\ Raipur, (C.G.), India \\ *Corresponding author
}

\begin{tabular}{|l|}
\hline Ke y w o r d s \\
Root nodules, \\
Rhizobium, \\
Soybean and \\
Biochemical \\
characterization
\end{tabular}

Total of eighteen (18) nodule samples of different 18 soybean cultivars were collected. Eighteen soybean varieties were grown in the Research field of Department of Plant Breeding and Genetics, College of Agriculture, Indira Gandhi KrishiVishwavidyalaya, Raipur (C.G.) during kharif2019-20. The present study was aimed to isolate the beneficial nitrogen fixing Rhizobium from root nodules of Soybean varieties to evaluate the effective symbiosis. The isolation, morphological and biochemical characterization were carried out in the laboratory of Department of Agricultural Microbiology, College of Agriculture, Raipur. Isolated Rhizobium strains were subjected to cultural and colony morphology tests on Yeast Extract Mannitol Agar (YEMA) from which top ten isolates showing good colony growth were selected for the biochemical characterization. After series of biochemical and Sugar Fermentation tests SRh-1, SRh-03, SRh-18, SRh-137 and SRh136were identified as promising strains. This study confirms the presence of promising indigenous Rhizobia in some Soybean varieties i.e., NRCSL 1, RSC 11-03, RKS 18, NRC 137 and NRC 136 over other varieties for effective symbiosis with indigenous rhizobia.

\section{Introduction}

The Golden bean, soybean is one of the legumes that have the ability to fix atmospheric nitrogen. It contains $40 \%$ vegetable protein, $20 \%$ oil, $21 \%$ Carbohydrates and 11.5\% Iron (Purohit and Kumar, 1998).The soyprotein's high biological value, protein efficiency ratio and essential amino acid pattern make it superior to most of plant proteins. New cultivars of soybean are being developed continuously (Akhandeet al., 2007). It is therefore important to screen these cultivars on the basis of efficient indigenous Rhizobia to determine their performance in terms of yield and adaptation to different ecologies. The bacteria colonize within root nodules, where it converts atmospheric nitrogen to ammonia and provides organic nitrogenous compounds to the plants. It has been proven that plant productivity increases when the Rhizobia are present in rhizosphere. It provides the major biological source of fixed nitrogen in agricultural soils. A well established practice for maintaining soil fertility has been 
evaluated for the cultivation of leguminous plants which replenish atmospheric nitrogen through symbiosis with rhizobia in rotation with non-leguminous plants. This study was aimed to isolate Rhizobium species from root nodules for better productivity.

There is an increasing demand of soybean for proteins and vegetable in tropics. To meet this requirement it is necessary to promote soybean production. Without inoculating tropical soils with Rhizobium many of the soybean varieties are unable to nodulate effectively. This inability to nodulate effectively with indigenous Rhizobium strain is one of the major factors preventing the production expansion of the soybean crop. Consequently it becomes inevitable to inoculate the crop in adequate Rhizobium (Deka and Azad, 2006). There is wide variation in the ability of Rhizobium strains to nodulate different soybean varieties. Thus, to understand responses and study the diversity and effectiveness of Rhizobia, isolation and characterization of Rhizobial population is necessary. The diversity and effectiveness of different isolates was studied on the basis of different biochemical tests viz. Triple sugar iron test, Starch utilization test and Catalase test (Tyagi et al., 2017). The isolates with an outstanding performance are identified, in a search for efficient and competitive strains for use in commercial inoculants in Chhattisgarh. Therefore in this study, the diversity of Rhizobial isolates from soybean root nodules, collected under field condition was studied.

\section{Materials and Methods}

This study was conducted in College of Agriculture, Raipur located at $21^{0} 16^{\prime} \mathrm{N}$ latitude and $81^{\circ} 36^{\prime} \mathrm{E}$ longitude, at an average elevation of 298.58 meters above the mean sea level (MSL). Total of eighteen (18) Soybean varieties were collected randomly from the Soybean field. The soybean varieties were collected at $50 \%$ flowering stage from the Research field of the Department of Plant Breeding and Genetics, College of Agriculture, Raipur and taken from the field to the laboratory for the isolation of Rhizobium from nodules.

Isolation: Healthy root nodules were washed with tap water thrice before streaking on agar plate. The nodules were sterilized externally using $95 \%$ alcohol for 1-4 minute, followed by washing with calcium hypochlorite solution $(10 \mathrm{~g} / 150 \mathrm{ml}$ distilled water) and crushing in a drop of sterile water. A loopful ground material was transferred to $5 \mathrm{ml}$ of sterile water, of which $0.1 \mathrm{ml}$ sample was spread onto the surface of Yeast Extract Mannitol Agar (YEMA). Plates were then incubated at $28^{\circ} \mathrm{C}$ for 48 hours. Well isolated typical single colonies were re-streaked on freshly prepared YEMA plates in order to obtain pure cultures. The Rhizobium isolates were designated as SRh-1613, SRh-1611, SRh-3108, SRh-136, SRh-1493, SRh-03, SRh-1, SRh-137, SRh-39, SRh-130, SRh-131, SRh-147, SRh-34, SRh-992, SRh-102, SRh11, SRh-18 and SRh-52. The eighteen soybean rhizobia isolated from 18 soybean varieties are given in Table 1 and named accordingly.

Morphological characteristics and Gramstaining of Rhizobium isolates: The colony characters viz. shape of the colony, size, elevation, margin, color, surface and motility characters were observed on YEMA medium. The Rhizobium isolates were gram-stained for more specified identification of the colonies. The bacterial cultures were smeared on the sterilized glass slides and fixed. Smear was stained with Crystal violet for one minute and rinsed with water. Then smear was flooded with Iodine solution for one minute. Excess of iodine solution was drained off and smear was decolorized with $95 \%$ alcohol for 30 seconds followed by washing with distilled water. 
Smear was counter stained with Safranin for 30 seconds, followed by washing with distilled water and air drying. T hen, observed under oil immersion objective of research microscope (Wadhwa et al., 2017).

Biochemical Tests: All the Rhizobium isolates were processed through biochemical tests viz. Catalase Test, Starch Hydrolysis/Amylase Test, as given in Bergey's manual of systematic bacteriology (2001). For starch utilization, inoculation by streaking of each isolate in Starch Agar Medium was done and incubated at $30^{\circ} \mathrm{C}$. After 24 hours of incubation iodine solution was flooded into the plates to determine the capability of microbes to use starch. A clear zone of inhibition around bacterial colonies indicated starch hydrolysis. The production of oxygen bubbles within a minute after addition of $\mathrm{H}_{2} \mathrm{O}_{2}$ on Trypticase soy agar slants with Rhizobium culture was the indicative of catalase positive test and no bubbles signifies negative result as described by Graham and Parker (1964).

Sugar Fermentation Tests: The isolates were also examined for fermentation of the various sugars including Glucose, Lactose, Fructose, Gas and $\mathrm{H}_{2} \mathrm{~S}$ production (Triple Sugar Iron Test, TSI) as described byAneja (2007). Bacterial cultures were inoculated into the triple sugar iron agar slants by stabbing through the center of the medium to the bottom and then streaked over the surface followed by incubating at $37^{\circ} \mathrm{C}$ for 2-5 days. The change in color of the slant and the formation of butt was observed.

Dehydrogenase activity in rhizosphere soil of different varieties of soybean:10 $\mathrm{g}$ fresh soil samples were mixed with $2.5 \mathrm{ml}$ of phosphate buffer, $0.2 \mathrm{~g} \mathrm{CaCO}_{3}$, and $1 \mathrm{ml}$ of $3 \%$ Triphenyl-tetrazolium chloride (TTC) and incubated at $25^{\circ} \mathrm{C}$ for $24 \mathrm{~h}$. After incubation, the samples were centrifuged at 3000rpm for
10 min. The supernatant liquid was discarded. The red-colored triphenyl-formazan (TPF) formed was extracted with methanol. $5 \mathrm{ml}$ methanol was added to each of the tubes and vigorously shaken for a few minutes. The operation was repeated twice with $10 \mathrm{ml}$ of methanol and centrifuged again the tubes. The absorbance of supernatant liquid obtained was measured for $K=485 \mathrm{~nm}$ as mentioned by Casida et al., (1964).

\section{Results and Discussion}

Out of eighteen samples of root nodules from Soybean all were found positive for the presence of Rhizobium. Gram Negative rods with circular, Raised and smooth edges colony with musky odour were observed in all 18 strains. The data depicted in Table 2 revealed that among 18 samples tested all the isolates were found positive for the presence of Rhizobium on the basis of regular white mucilaginous colony growth on YEMA medium. The top ten isolates having good colony growth were preserved on YEMA medium slants for further characterization.

Out of 18 strains, 10rhizobia strains showing good colony growth were screened through a series of various biochemical and Sugar fermentative tests depicted in Table 3. All the Rhizobium isolates were able to show starch hydrolysis. Two of the Rhizobium isolates i.e.SRh-1 and SRh-136 showed good clear zone.

All the top 10 Rhizobium isolates showed positive for catalase test. This finding is in close agreement with Saldana et al., (2003); Shahzad et al., (2012) and Gauri et al., (2017). All the top ten Rhizobium isolates showed positive test for glucose, lactose and sucrose fermentation. Similar results were reported by Sharma et al., (2009) and Tyagi et al. (2017). 
Table.1 Isolation of Rhizobium strains from root nodules of different Soybean varieties

\begin{tabular}{|l|c|c|}
\hline S. No. & $\begin{array}{c}\text { Soybean Rhizobium } \\
\text { Isolates }\end{array}$ & $\begin{array}{c}\text { Different } \\
\text { which Rhizobium isolated }\end{array}$ \\
\hline $\mathbf{1 .}$ & SRh-1613 & PS 1613 \\
\hline $\mathbf{2 .}$ & SRh-1611 & PS 1611 \\
\hline $\mathbf{3 .}$ & SRh-3108 & DS 3108 \\
\hline $\mathbf{4 .}$ & SRh-136 & NRC 136 \\
\hline $\mathbf{5 .}$ & SRh-1493 & MACS 1493 \\
\hline $\mathbf{6 .}$ & SRh-03 & RSC $11-03$ \\
\hline $\mathbf{7 .}$ & SRh-1 & NRCSL 1 \\
\hline $\mathbf{8 .}$ & SRh-137 & NRC 137 \\
\hline $\mathbf{9 .}$ & SRh-39 & AMS $100-39$ \\
\hline $\mathbf{1 0 .}$ & SRh-130 & NRC 130 \\
\hline $\mathbf{1 1 .}$ & SRh-131 & NRC 131 \\
\hline $\mathbf{1 2 .}$ & SRh-147 & NRC 147 \\
\hline $\mathbf{1 3 .}$ & SRh-34 & DSb34 \\
\hline $\mathbf{1 4}$ & SRh-992 & KDS 992 \\
\hline $\mathbf{1 5}$. & SRh-102 & BAUS 102 \\
\hline $\mathbf{1 6 .}$ & SRh-11 & SKF-SP-11 \\
\hline $\mathbf{1 7 .}$ & SRh-18 & RKS 18 \\
\hline $\mathbf{1 8 .}$ & SRh-52 & JS $97-52$ \\
\hline
\end{tabular}

Table.2 Colony morphology and Gram's reaction of indigenous Rhizobium Isolates of Soybean varieties

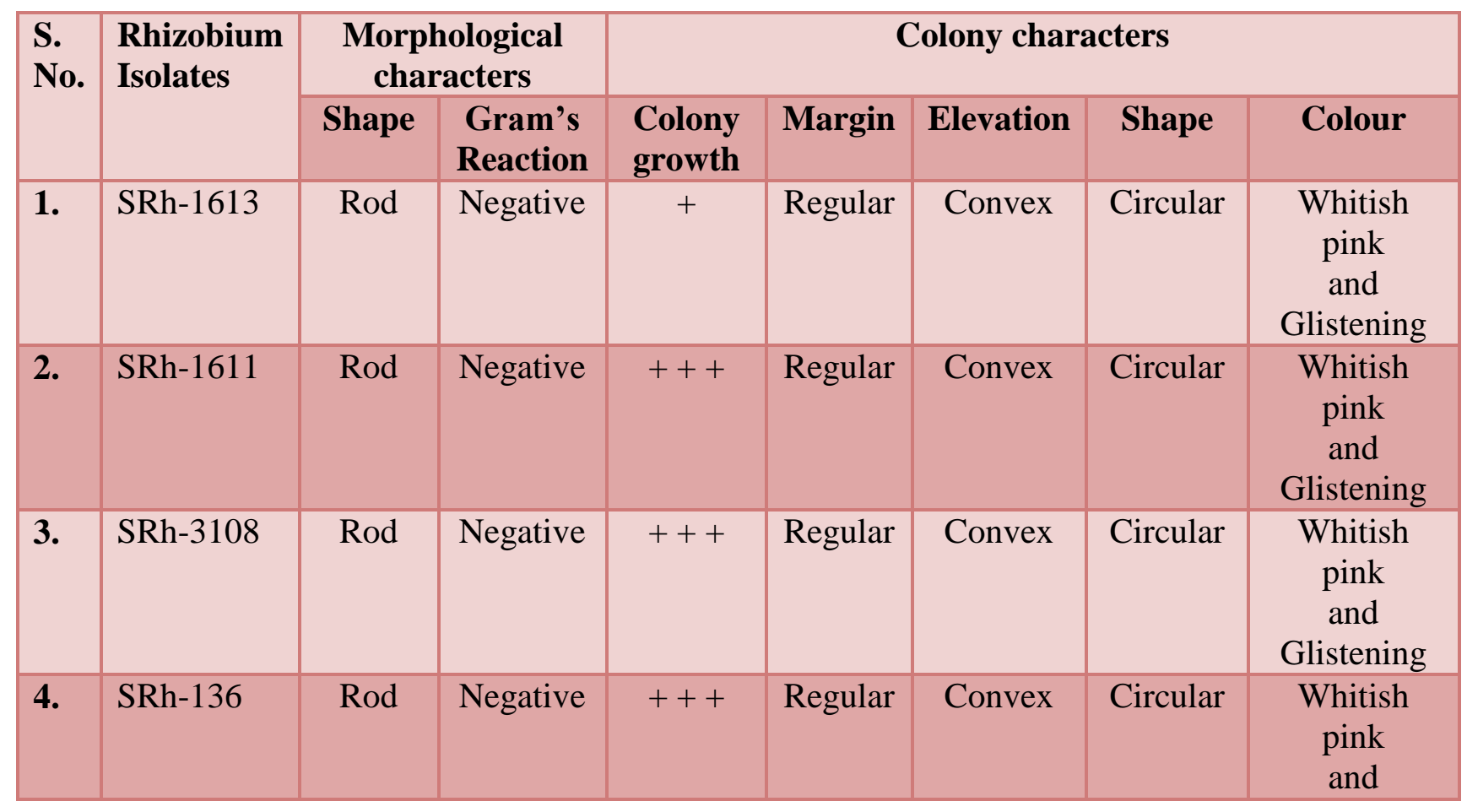




\begin{tabular}{|c|c|c|c|c|c|c|c|c|}
\hline & & & & & & & & Glistening \\
\hline 5. & SRh-1493 & Rod & Negative & + & Regular & Convex & Circular & $\begin{array}{l}\text { Whitish } \\
\text { pink } \\
\text { and } \\
\text { Glistening }\end{array}$ \\
\hline 6. & SRh-03 & Rod & Negative & +++ & Regular & Convex & Circular & $\begin{array}{l}\text { Whitish } \\
\text { pink } \\
\text { and } \\
\text { Glistening }\end{array}$ \\
\hline 7. & SRh-1 & Rod & Negative & +++ & Regular & Convex & Circular & $\begin{array}{l}\text { Whitish } \\
\text { pink and } \\
\text { Glistening }\end{array}$ \\
\hline 8. & SRh-137 & Rod & Negative & +++ & Regular & Convex & Circular & $\begin{array}{l}\text { Whitish } \\
\text { pink and } \\
\text { Glistening }\end{array}$ \\
\hline 9. & SRh-39 & Rod & Negative & + & Regular & Convex & Circular & $\begin{array}{l}\text { Whitish } \\
\text { pink and } \\
\text { Glistening }\end{array}$ \\
\hline 10. & SRh-130 & Rod & Negative & +++ & Regular & Convex & Circular & $\begin{array}{l}\text { Whitish } \\
\text { pink and } \\
\text { Glistening }\end{array}$ \\
\hline 11. & SRh-131 & Rod & Negative & +++ & Regular & Convex & Circular & $\begin{array}{l}\text { Whitish } \\
\text { pink and } \\
\text { Glistening }\end{array}$ \\
\hline 12. & SRh-147 & Rod & Negative & +++ & Regular & Convex & Circular & $\begin{array}{l}\text { Whitish } \\
\text { pink and } \\
\text { Glistening }\end{array}$ \\
\hline 13. & SRh-34 & Rod & Negative & + & Regular & Convex & Circular & $\begin{array}{l}\text { Whitish } \\
\text { pink and } \\
\text { Glistening }\end{array}$ \\
\hline 14. & SRh-992 & Rod & Negative & + & Regular & Convex & Circular & $\begin{array}{l}\text { Whitish } \\
\text { pink and } \\
\text { Glistening }\end{array}$ \\
\hline 15. & SRh-102 & Rod & Negative & + & Regular & Convex & Circular & $\begin{array}{l}\text { Whitish } \\
\text { pink and } \\
\text { Glistening }\end{array}$ \\
\hline 16. & SRh-11 & Rod & Negative & + & Regular & Convex & Circular & $\begin{array}{l}\text { Whitish } \\
\text { pink and } \\
\text { Glistening }\end{array}$ \\
\hline 17. & SRh-18 & Rod & Negative & +++ & Regular & Convex & Circular & $\begin{array}{l}\text { Whitish } \\
\text { pink and } \\
\text { Glistening }\end{array}$ \\
\hline 18. & SRh-52 & Rod & Negative & + & Regular & Convex & Circular & $\begin{array}{l}\text { Whitish } \\
\text { pink and } \\
\text { Glistening }\end{array}$ \\
\hline
\end{tabular}


Table.3 Biochemical characterization of Rhizobial isolates of Soybean

\begin{tabular}{|c|c|c|c|c|c|c|c|c|c|}
\hline \multirow[t]{3}{*}{ S. No. } & \multirow{3}{*}{$\begin{array}{l}\text { Soybean } \\
\text { varieties }\end{array}$} & \multirow{3}{*}{$\begin{array}{l}\text { Rhizobium } \\
\text { Isolates }\end{array}$} & \multicolumn{7}{|c|}{ Biochemical Characterization } \\
\hline & & & \multirow{2}{*}{$\begin{array}{c}\text { Amylase } \\
\text { test }\end{array}$} & \multirow{2}{*}{$\begin{array}{c}\text { Catalase } \\
\text { test }\end{array}$} & \multicolumn{5}{|c|}{ Utilization of Carbon source (TSI) } \\
\hline & & & & & $\begin{array}{c}\text { Glucose } \\
\text { ferment } \\
\text { ation }\end{array}$ & $\begin{array}{c}\text { Lactose } \\
\text { fermentati } \\
\text { on }\end{array}$ & $\begin{array}{c}\text { Sucrose } \\
\text { fermentatio } \\
n\end{array}$ & $\begin{array}{l}\text { Gas } \\
\text { produc } \\
\text { tion }\end{array}$ & $\begin{array}{c}\mathrm{H}_{2} \mathrm{~S} \\
\text { produc } \\
\text { tion }\end{array}$ \\
\hline 1. & NRCSL 1 & SRh-1 & +++ & +++ & + & + & + & + & + \\
\hline 2. & RSC 11-03 & SRh-03 & +++ & +++ & + & + & + & + & + \\
\hline 3. & RKS 18 & SRh-18 & +++ & +++ & + & + & + & + & + \\
\hline 4. & NRC 137 & SRh-137 & +++ & +++ & + & + & + & - & - \\
\hline 5. & NRC 136 & SRh-136 & +++ & +++ & + & + & + & - & - \\
\hline 6. & NRC 147 & SRh-147 & ++ & ++ & + & + & + & - & - \\
\hline 7. & NRC 131 & SRh-131 & ++ & ++ & + & + & + & - & - \\
\hline 8. & DS 3108 & SRh-3108 & ++ & ++ & + & + & + & - & - \\
\hline 9. & PS 1611 & SRh-1611 & ++ & ++ & + & + & + & - & - \\
\hline 10. & NRC 130 & SRh-130 & ++ & ++ & + & + & + & - & - \\
\hline
\end{tabular}

Fig.1 Dehydrogenase activity in rhizosphere soil of different Soybean varieties

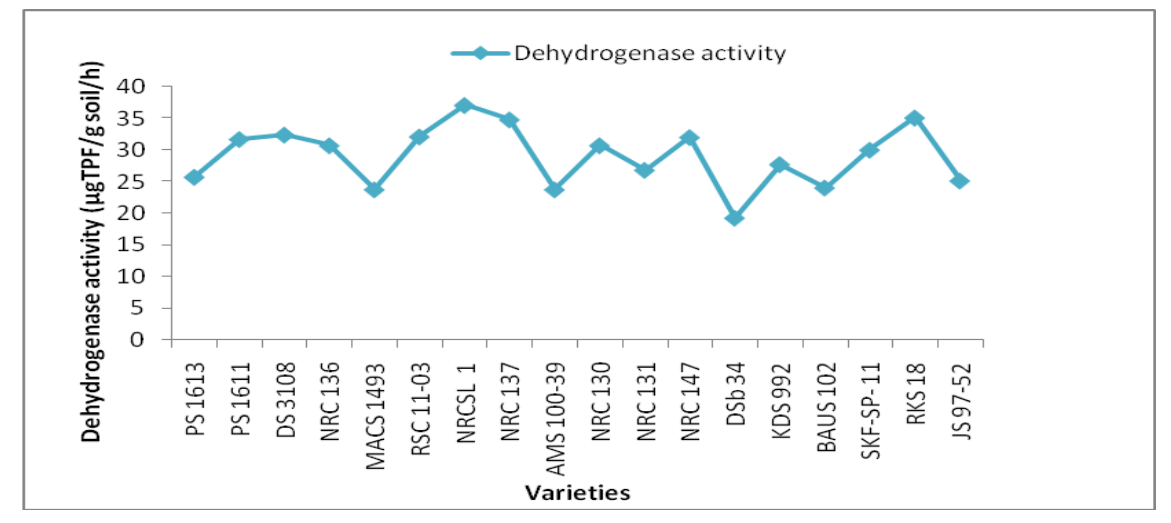

These findings corroborate with the results of Michael (2006); Singh (2008) and Erum (2008) who also reported these sugar tests positive during isolation and characterization of Rhizobium. The three isolates (SRh-1, SRh-03 and SRh-18) were shown positive for the gas and $\mathrm{H}_{2} \mathrm{~S}$ production, while other seven isolates were shown negative for the same. After screening through various biochemical and Sugar fermentative tests the top five isolates were SRh-1, SRh-03, SRh-18, SRh137 and SRh-136. The dehydrogenase activity of rhizosphere soils from all target soybean varieties has been depicted in Fig 1.The DHA was observed between 19.2 to $37.1 \mu \mathrm{gTPF} / \mathrm{g}$ soil/h. The maximum dehydrogenase activity was shown by soil of soybean variety NRCSL 1 (37.1 $\mu \mathrm{gTPF} / \mathrm{g}$ soil/h) followed by RKS 18 (35.1 $\mu \mathrm{gTPF} / \mathrm{g}$ soil/h).

In conclusion from biochemical studies of indigenous soybean rhizobia isolates and microbial activities in Soybean rhizosphere soils, it is seen that SRh-1, SRh-03, SRh-18, SRh-137 and SRh-136 were promising indigenous Rhizobium isolates. Screening of indigenous strains as per local Chhattisgarh agro-climatic condition is being significant 
and can be used as bio-inoculants in Soybean crop cultivation for enhancing the productivity.

\section{Acknowledgement}

The authors are thankful to Department of Plant Breeding and Genetics and Department of Agricultural Microbiology, IGKV, Raipur (C.G.) for providing necessary facilities and continuous encouragement in carrying out the present investigation.

\section{References}

Akande, S.R., Owolade, O.F. and Ayanwole, J.A. 2007. Field evaluation of soybean varieties sat Ilorin in the southern guinea savanna ecology of Nigeria. African Journal of Agricultural Research, 2: 356-359.

Aneja, K.R., 2007. Experiments in microbiology, plant pathology and biotechnology. New Age International.

Bergey's Manual Trust, B.S., 2001.Manual of Systematic Bacteriology, vol. 1.

Casida, L.E., Klein, D., Santoro, T., 1964.Soil dehydrogenase activity. Soil Science 98, 371-376.

Cross, A. and Sohi, S.P., 2011. The priming potential of biochar products in relation to labile carbon contents and soil organic matter status. Soil biology and biochemistry, 43(10), pp.2127-2134.

Deka, A.K. and Azad, P., 2006. Isolation of rhizobium strains: cultural and biochemical characteristics. Legume Research- An International Journal, 29(3), pp.209-212.

Erum, S. and Bano, A., 2008. Variation in phytohormone production in Rhizobium strains at different altitudes of northern areas of Pakistan. Int. J. Agric. Biol, 10, pp.536-540.

Gauri, A.K.S., R.P. Bhatt, S. Pant, M.K. Bedi and A. Naglot 2011. Characterization of Rhizobium isolated from root nodules of Trifoliumal exandrium. J. Agric. Technol. 7(6): 1705-1723. Graham, P.H. 1963.

Małachowska-Jutsz, A., Matyja, K., 2019.Discussion on methods of soil dehydrogenase determination. Int. J. Environ. Sci. Technol. 16, 7777-7790. https://doi.org/10.1007/s13762-01902375-7.

Michael, J. S and P. H. Grahm, 2006. Root and stem nodule bacteria of legumes. Prokaryotes 2: 818- 841.

Nigam, M.S. and Xaxlo, P.D., 2017. Isolation, biochemical characterization and metabolic fingerprinting of rhizobium from root nodules of Clitoriaternatea.

RAO, N.S., 1988. Ten decades of research on biological nitrogen fixation. Current science, pp.710-717.

Purohit, S. S. and Kumar, A.,1998. Plant Physiology, Agro Botanical Publishers (Incua)/Agro Botanica, Bikaner. 289.

Saldana, G., Martinez-Alcantara, V., Vinardell, J.M., Bellogín, R., RuízSainz, J.E. and Balatti, P.A. 2003. Genetic diversity of fast-growing rhizobia that nodulate soybean (Glycine $\max$ L. Merr). Archives of microbiology, 180(1), pp.45-52.

Singh, B., Kaur, R. and Singh, K., 2008. Characterization of Rhizobium strain isolated from the roots of Trigonella foenumgraecum (fenugreek). African Journal of Biotechnology, 7(20).

Shahzad, F., Shafee, M., Abbas, F., Babar, S., Tariq, M.M. and Ahmad, Z. 2012. Isolation and biochemical characterization of Rhizobium meliloti from root nodules of Alfalfa (Medico sativa). J. Animal Plant Sci. 22(2): 522524.

Sharma, M.P., Srivastava, K. and Sharma, S.K., $2009 . \quad$ Biochemical characterization and metabolic diversity of soybean rhizobia isolated from 
Malwa region of Central India.

Tyagi, A., Kumar, V. and Tomar, A., 2017. Isolation, identification, biochemical and antibiotic sensitivity characterization of Rhizobium strains from Vigna mungo (L.) Hepper, Cicer arietinum (L.) and Vigna radiata (L.) Wilczek in Muzaffarnagar, Uttar Pradesh, India. Int J CurrMicrobiol App Sci, 6, pp.2024-2035.

Wadhwa, N., Chen, J.G., Sellon, J.B., Wei, D., Rubinstein, M., Ghaffari, R.,
Freeman, D.M., Büyüköztürk, O., Wang, P., Sun, S. and Kang, S.H., 2017.Motion microscopy for visualizing and quantifying small motions. Proceedings of the National Academy of Sciences, 114(44), pp.11639-11644.

Wolinska, A. and Stępniewska, Z., 2012. Dehydrogenase activity in the soil environment. Dehydrogenases, pp.183210.

\section{How to cite this article:}

Shanti, Diptimayee Dash and Tapas Chowdhury. 2021. Isolation and Biochemical Characterization of Indigenous Rhizobium Strains from Root Nodules of Field Grown Soybean Crop. Int.J.Curr.Microbiol.App.Sci. 10(01): 3429-3436. doi: https://doi.org/10.20546/ijcmas.2021.1001.404 